\title{
TWO TYPES OF NOUN INCORPORATION: A LEXICAL ANALYSIS
}

\author{
SARA Thomas Rosen \\ Brandeis University
}

In recent work Noun Incorporation has been argued to result from head movement, in which the head of an object noun phrase moves into the verb, creating a complex verb. This paper argues instead that NI derives from word formation rules applying in the lexicon, presyntactically. On the basis of clusters of grammatical properties associated with NI, it is apparent that there are two separate word formation processes that languages may choose. In one, when a noun root combines with a verb root, the argument structure of the verb is altered such that the complex verb takes one less argument. In the other form of NI, when a noun root combines with a verb root, the argument structure of the complex verb is unaltered. It is shown that the predicted grammatical properties associated with the change or lack of change in argument structure follow.*

1. INTRODUCTION AND SKETCH OF LEXICAL ANALYSIS. Noun Incorporation (NI) is a process whereby nouns combine with verbs to produce a complex verb, as in the Onondaga sentence in $1 \mathrm{~b}$ and the Niuean sentence in $2 \mathrm{~b}$. Sentences like $1 \mathrm{~b}$ and $2 \mathrm{~b}$ have nonincorporated counterparts, as illustrated in la and $2 \mathrm{a} .^{1}$

* The research reported in this paper was supported in part by NSF grant IST-8420073 to Brandeis University. I wish to mention the contributions of several people to this work. Thanks go especially to Jane Grimshaw for vast amounts of help and encouragement. My appreciation extends also to Janet Benger, Joan Bresnan, Claudia Borgonovo, Don Frantz, Ken Hale, Mark Hewitt, Joan Maling, Alec Marantz, Ellen Woolford, and two anonymous reviewers. A version of this paper was presented to the 1987 Seminar on Complex Predicates at MIT; I thank the members of that class for their helpful questions and comments.

\begin{tabular}{llllll}
\multicolumn{2}{c}{${ }^{1}$ A list of abbreviations used throughout this paper follows: } & & \\
1 & first person & du & dual & pl & plural \\
2 & second person & EMPH & emphasis & PRED & predicator \\
3 & third person & ERG & ergative & PRN & pronoun \\
ABS & absolutive & F & feminine & PROG & progressive \\
AGR & agreement & HAB & habitual & PUNC & punctual \\
AMB & ambulative & INCH & inchoative & Q & question \\
AOR & aorist & INDIC & indicative & REL & relative \\
APASS & antipassive & INST & instrumental & REP & repetitive \\
ART & article & INTR & intransitive & REV & reversive \\
ASP & aspectual marker & ITER & iterative & S & subject \\
ASSN & assertion & LOC & locative & Sg & singular \\
CAUS & causative & M & masculine & SPEC & specifier \\
COIN & coincident & N & neuter & STAT & stative \\
COMIT & comitative & NEG & negative & SUF & suffix \\
CONT & continuative & NM & nominalizer & TNS & tense \\
DAT & dative & NOM & nominative & TRANS & transitive \\
DISLOC & dislocative & OBJ & objective & TRS & translocative \\
DIST & distributive & PAST & past tense & UNAN & unanalyzed \\
DPL & duplicative & PERF & perfective & Z & zoic
\end{tabular}

In order to be consistent throughout the paper, I have indicated all glottal stops with ?. nasalization with - and long vowels with a colon (:). Also for consistency, and to reflect my theoretical position, all English glosses of agreement affixes are indicated by person, number, and gender (e.g. $3 \mathrm{sgM}$ ) rather than with a pronoun (he). 
(1) Onondaga (Woodbury 1975:10)
a. wa Phahninü? ne? oyékwa?
TNS.3sg.3N.buy.ASP ART 3N.tobacco.NM
'He bought the tobacco.'
b. wa Phaye?kwahni:nu?
TNS.3sg.3N.tobacco.buy.ASP
'He bought tobacco.'

(2) Niuean (Seiter 1980:69)

a. Takafaga tu:mau ni: e ia e tau ika. ${ }^{2}$

hunt always EMPH ERG he ABS PL fish

'He's always hunting fish.' (= He's always fishing)

b. Takafaga ika tu:mau ni: a ia.

hunt fish always EMPH ABS he

'He's always fish-hunting.' (= He's always fishing.)

It has been suggested, most notably by Sadock 1980, 1985a, 1986 and by Baker (1988a:Ch. 3), that noun incorporation is a syntactic rule that realizes the head of the direct object noun phrase or the head of the subject of an unaccusative verb within the verbal complex, either by movement (Baker) or by coanalysis (Sadock). The result is a morphologically complex verb, containing a noun root that is linked to the direct object position (either by a trace relation or by the disjunction of the syntactic and morphological analyses). In $1 \mathrm{~b}$ and $2 \mathrm{~b}$, the verbs, which are ordinarily transitive, have no overt direct object. Examples of NI out of the subject of an unaccusative verb are in 6 and 7. An alternative to the syntactic approach to NI is to posit that the complex verb is derived lexically, by a word-formation process similar to compounding. Mithun 1984, 1986a and Di Sciullo \& Williams (1987:64-68) suggest that NI is a lexical process. The research reported in the current paper supports a lexical analysis of NI, but goes beyond the syntactic/lexical distinction to show that there are two distinct types of NI. ${ }^{3}$ This paper explores the grammatical properties associated with noun incorporation, showing that they follow directly from a lexical analysis that distinguishes two different cases of NI.

In this theory, there are two kinds of NI represented across languages. One is like simple compounding, similar to compounding in English. In this form of NI, when a noun and verb combine to form a complex verb, one argument of the simple verb is satisfied within the verb. ${ }^{4}$ Thus, if a simple verb takes

\footnotetext{
${ }^{2}$ The ergative/absolutive casa markers in Niuean have a different phonological form depending on whether the noun is a common noun, or a pronoun or proper noun (Seiter 1980):

$\begin{array}{lcc} & \text { COMMON NOUN } & \text { PROPER-/PR } \\ \text { ERGATIVE } & \text { he } & \mathrm{e} \\ \text { ABSOLUTIVE } & \mathrm{e} & \mathrm{a}\end{array}$

${ }^{3}$ Mithun 1984 delineated four types of NI based on four distinct discourse functions of incorporation, including compound and classificatory functions, and also argued for a lexical approach to NI. The reasoning used to argue for the two types of NI in my theory is purely syntactic and not discourse/functional.

${ }^{4}$ The few English verbal compounds that exist may not result in an intransitive verb (e.g. babysit). However, these are clearly backformations from noun compounds, and are completely unproductive (Selkirk 1983:16-17, Mithun 1984).
} 
two arguments, (x,y), the $\mathrm{N}+\mathrm{V}$ complex takes only one: (x), an external argument. The verb is then intransitive. I will call this Compound NI. Compound NI affects the argument structure of the simple, non-compounded form of a verb, as illustrated in the Niuean sentences in $2 a-b$.

In other languages, when the object incorporates into the verb, the verb's transitivity is completely unaffected, which makes it look quite different from compounding. In this form of NI, unlike in Compound NI, the incorporated noun does not satisfy an argument of the verb. If the simple verb takes a direct object argument, then the complex verb also co-occurs with a direct object NP, which is required to satisfy the verb's argument structure. The direct object argument and the incorporated noun are linked semantically in much the same way that a noun classifier is linked semantically to the noun it classifies. I call this Classifier NI, because the incorporated noun acts like a classifier on the noun it is associated with; the reasons for this will become clear in a later section.

When one explores the data on NI, one finds that those languages that have Classifier NI also allow what is commonly called 'stranding', a process whereby an NP modifier is left with no head noun, while a noun with the same semantic reference is incorporated into the verb. I refer to the stranded items as 'nullhead modifiers', because they modify the head noun, which is null. As argued in a later section, the range of stranding facts in these languages follows from an interaction between NI and an independent process in the languages-the existence of null head modifiers.

The division of NI into the two types argued for here is supported by the syntactic behavior of NI, specifically the identification of a cluster of properties associated with it. Further support for this distinction comes from the function of NI as expounded in Mithun 1984. Mithun delineated four different types of NI on a functional or discourse basis. Her first three functional categories of NI correspond to my Compound NI, and her fourth corresponds to my Classifier NI. Mithun's classification lends functional credence to the division proposed here purely on grammatical grounds.

For ease of exposition, a list of languages that have Classifier and Compound $\mathrm{NI}$ is given in Table 1. I will refer to these languages throughout the paper. This is not an exhaustive list of incorporating languages; it contains the languages covered in the research reported here.

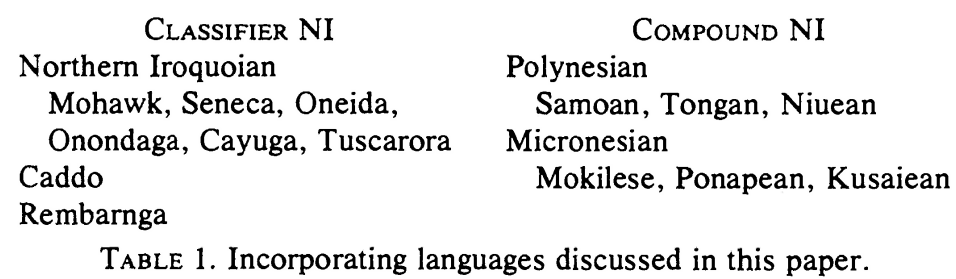

The hypothesis that there are two kinds of NI leads to predictions about the grammatical properties one should find associated with incorporation. These properties include the effects on the transitivity of the verb, the ability of determiners and modifiers to appear without a head noun (commonly called stranding), and the co-occurrence of the complex verb with full NPs in direct 
object position (doubling). In the following sections of this paper, I show that incorporating languages display clusters of grammatical properties as predicted by Classifier and Compound NI structures. I also discuss two alternative syntactic approaches to noun incorporation-syntactic movement and autolexical syntax-and show that neither one predicts the grammatical properties that these languages display. In its totality, this paper shows that the identification of the two independent types of NI, within a lexical account, captures the overall properties of the constructions that occur.

2. Classifier NI. An example of Classifier noun incorporation was given in 1. The name Classifier NI was given because the incorporated noun is similar to a classifier in that the object noun phrase, if overt, must be more specific than (or, in some languages, at least as specific as) the incorporated noun (see Woodbury 1975 , for example); thus, it would be impossible to say 'I dog-bought an animal' in Iroquoian. The equivalent of 'I animal-bought a dog' is fine, as is ' $I$ animal-bought a large (animal)' (Janet Benger, personal communication 1986).

In Classifier NI, the direct object argument is not satisfied within the complex verb, and therefore an object NP must co-occur with NI to satisfy the verb's argument structure. However, the incorporated noun places a selectional restriction on the verb, such that the object NP must be within the class of objects delineated by the incorporated noun root. This explains the fact noted above concerning the specificity requirement on the NP associated with the incorporated noun. Thus, the equivalent of 'I animal-bought a dog' is fine because 'dog' is within the class delineated by the incorporated noun 'animal'. The same is true for 'I animal-bought a large (animal)'. However, in 'I dog-bought an animal', animal is not included in the class of items that are 'dogs'. The latter sentence would be judged ungrammatical because the selectional restrictions placed on the verb are not met. Therefore, the claim is that the only argument structure effect of Classifier NI is the extra selectional restriction placed on the verb.

The range of possible direct object NPs following an incorporated noun are illustrated in the diagrams $3 a-c$. The NP can be completely empty ( $3 a$ ), as in pro-drop; the $\mathrm{N}$ or $\mathrm{N}^{\prime}$ can be empty (3b), commonly referred to as 'stranding'; or the entire NP can be filled, often called 'doubling'. 5

(3) Classifier NI

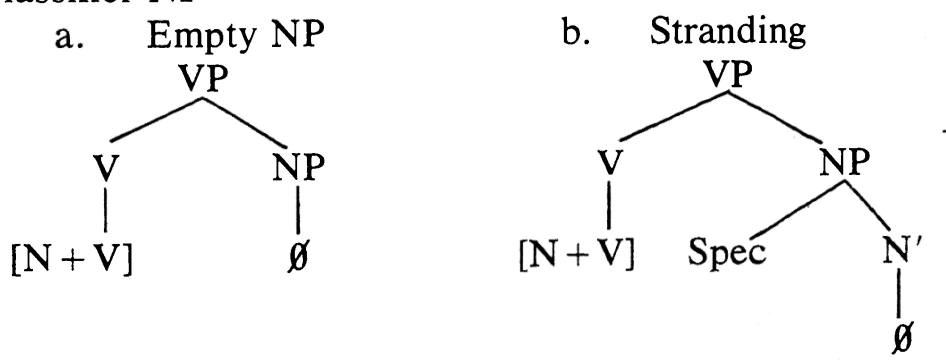

\footnotetext{
${ }^{5}$ Some of the arguments expounded in this section were independently made in Di Sciullo \& Williams (1987:63-68). In particular, they noticed the independent well-formedness of stranded modifiers, and they also point to the doubling facts.
} 


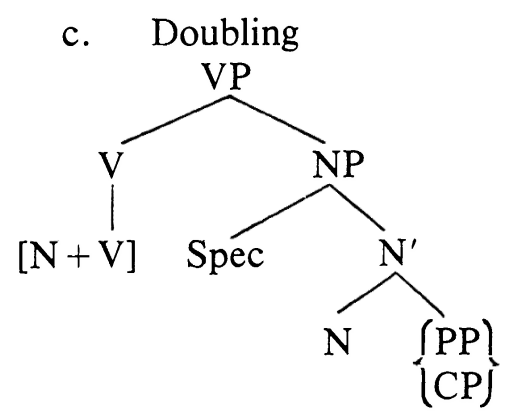

One important fact about all of the Classifier incorporating languages is that they all freely allow pro-drop in all positions. Pro-drop in Onondaga is illustrated below:

(4) Onondaga (Mithun \& Woodbury 1980:62)

$$
\begin{aligned}
& \text {... shükw-atéén-ò }{ }^{2} k t-a \text { ? ka-Rühi-a?-ke hẽ-i?trū-? } \\
& \text { 3M.lpl-UNAN-complete-sTAT N-sky-SUF-LOC M-dwell-sTAT } \\
& w a^{2}-h a-\tilde{u}-? \text { [pro] [pro]. } \\
& \text { AOR-M.M-give-PUNC }
\end{aligned}
$$

'He who created us and lives in the sky gave him (this knowledge).'

I have added [pro] twice at the end of sentence 4 to indicate empty pronominal elements (linear position irrelevant). The 'knowledge' mentioned in the translation of 4 is inferred from earlier discourse, and is therefore understood as the theme of 'give'. The goal understood as 'him' is apparent from the agreement marker on the verb. ${ }^{6}$

2.1. Stranding OF MODIFIERS AND NUll PRO-FORMS. In Classifier NI, incorporated nouns can be associated with NPs that have determiners, modifiers, and possessors, but no head noun. This is called 'stranding' in the literature, and it arises when the direct object NP is partly null (as diagrammed in 3b). The stranded element modifies the null head of the direct object NP. The present theory attributes the stranding facts to an independent phenomenon in the language (the existence of null-head modifiers in general). An inevitable consequence of a language with the two properties - NI and null pro-formsis that the two will interact, and indeed they do.

The direct object NP in a clause with an incorporated noun appears just like any NP in the language. If the form of the NP is truly independent of the incorporated noun, then null-head modifiers (often called stranded modifiers) should be possible whether a noun is incorporated or not. The analysis assumes

\footnotetext{
${ }^{6}$ Some Iroquoianists analyze the agreement markers as the arguments of the verb, with the NPs external to the verb complex serving as adjuncts that may double the arguments (Mithun 1986b, for example). Notice, however, that if the agreement morphemes are the arguments, then one might be forced to say that a verb like 'give' in 4 has only two arguments, the agent and goal; the theme would not be an argument, because it does not appear as a prefix on the verb. Because of the various problems with the hypothesis that the agreement morphemes are actually the arguments, I will refer to such constructions as pro-drop, meaning that the verbal prefixes are simply agreement prefixes, and the actual arguments are outside the verb, with pro-drop applying freely. It should be noted, however, that the terms used to refer to the verbal prefixes and the independent NPs make no difference for the theory put forth in this paper.
} 
that null objects are independent of NI, and thus null-head modifiers should occur independent of NI. The crucial evidence for such independence requires a sentence with a simple transitive verb, and a direct object NP with a null head. Mithun 1984 presents evidence for null heads of NPs in Mohawk. In 5a, the theme/patient 'dress' is incorporated, the head of the object NP is empty, and the modifier 'dotted' is stranded. In 5b, however, the modifier 'dotted' is again left stranded, but this time the head $\mathrm{N}$ does not appear in the sentence at all, and there is no incorporated noun.

(5) Mohawk (Mithun 1984:870)

a. Kanekwarúnyu wa?-k-akya Ptawi ’tsher-ú:ni.

3N.dotted.DIST PAST-1sg.3N-dress-make ${ }^{7}$

'I made a polka-dotted dress.'

b. Kanekwarúnyu wa Pkatkáhtho.

3N.dotted.DIST PAST.1sg.3N.see

'I saw a dotted (one).'

It is interesting to note that in $5 \mathrm{~b}$ the adjective kanekwarunyu 'dotted' agrees in gender (neuter) with a phonologically nonexistent noun, and that the agreement pattern is the same with and without incorporation. This presents strong evidence for a null $\mathrm{N}$ or $\mathrm{N}^{\prime}$; agreement is a function of the null position, and not of an incorporated noun.

Further evidence of the syntactic independence of the direct object and the incorporated noun is illustrated in the stranding of demonstratives and quantifiers in Caddo, another Native American language. In 6a and 7a, a noun stem is incorporated, whereas in $6 \mathrm{~b}$ and $7 \mathrm{~b}$ no incorporation has taken place. The NPs are identical in the two sentences, indicating that the form of the NP (in particular, the empty head) is not in any way dependent upon NI.

(6) Caddo (Mithun 1984:865-6)

a. ná: kan-núh-?a?

that water-run.out-will

'That water will run out.'

b. ná: Píyúh ?a?

that run.out.will

'That will run out.'

(7) Caddo (Mithun 1984:866)

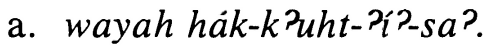

a.lot PROG-grass-be.grow-PROG

'There is a lot of grass.'

b. wayah háh-?i?-sa?

a.lot PROG-be.grow-PROG

'There is a lot.'

\footnotetext{
${ }^{7}$ Mithun glosses the agreement prefix $-k$ - with only subject agreement. However, agreement with a nonhuman object is always realized as $\emptyset$ on the surface, and therefore when the object is nonhuman, transitive agreement is identical to intransitive agreement (Postal 1979:140ff, Williams 1976:170). Therefore, I have glossed the agreement in 5 as a transitive prefix; explanation and evidence for this is provided in $\$ 2.2$.
} 
To further establish the independent well-formedness of null-head modifiers, one must also look at NPs not ordinarily associated with NI. NI is said to be associated with the direct object NP, or the subject of an unaccusative verb. However, in the Iroquoian and Caddoan languages any NP can have a null head. Examples of modifier stranding in subject position and adjunct position are given in 8 and 9.

(8) Tuscarora (Mithun \& Woodbury 1980:109)

a. ... kye:ni:kv: ha? kye? ra-kwatihs $\emptyset$ yah-wa-hra-kwa?n-

this that that M-young $\varnothing$ TRS-AOR-M-side-

ate:-? kye? $\theta$-hr-e? ra-kwatihs $\varnothing$

encircle-PUNC that REP-M-go M-young $\varnothing$

'This young (man) who had gone around the other side, came back again as a young (man).'

b. U:nv kye:ni:kv: $\emptyset$ a-a-hr-ahr-ku-?

now this $\varnothing$ REP-AOR-M-go-REV-PUNC

$y a h-v \theta-a-h r a-k w a{ }^{2} n-a \theta e:-?{ }^{8}$

TRS-REP-AOR-M-side-encircle-PUNC

'Now this (man) went back to where he came from.'

(9) Seneca (Mithun \& Woodbury 1980:51)

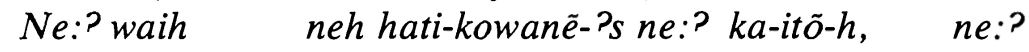

ASSN specifically the Mpl-big-HAB ASSN N-mean-HAB ASSN

hati-hsẽn-owanẽ-?s-kwa? ne?ho-öwe-shõ?

Mpl-name-big-HAB-PAST that-UNAN-PL

'Big (ones) means that they were chiefs at that time.'

Rembarnga, a Northern Australian language, is an example of a Classifier NI language that appears to have a restricted range of null-head modifiers. McKay 1975 gives examples of null-headed demonstratives only, as in 10 .

(10) Rembarnga (McKay 1975:120)

walay nanta-kan ya-pa-wa.

then that-DAT 3.OBJ.1sg.TRANS.S-leave-PAST.PUNC

'so (then) because of that [fear] I left [shooting the buffalo].'

Ex. 11 shows that stranding demonstratives in NI constructions is possible as well. McKay gives no examples of stranding modifiers other than demonstratives in NI constructions.

(11) Rembarnga (McKay 1975:291)

yar-kari-pete?-min

nanta-Ø-ma.

3sg.OBJ.1pl.TRANS.S-wounded-carry-PAST.PUNC that-NOM-UNAN

'We carried that wounded man.'

It is possible that the demonstratives are actually nominalized (McKay refers to them as 'nominal demonstratives', and in this instance the demonstrative appears to have a nominative case marker, used to mark objects and subjects of ergative verbs). If lone demonstratives are nominalized, then it becomes clear that null-head modifiers do not exist in Rembarnga, and neither does

\footnotetext{
${ }^{8}$ Mithun \& Woodbury 1980 report the morpheme $k w a{ }^{2} n$ in $8 \mathrm{~b}$ as $k w a: n$ in their morphological analysis, but as $k w a{ }^{2} n$ elsewhere (including the running text of the same sentence). I have chosen to use the form $k w a^{2} n$ to be consistent with their other examples.
} 
stranding (as predicted by my theory). Ex. 11 would then be a case of doubling, which will be shown in $\$ 2.3$ to be possible in Rembarnga.

If one were to subscribe to a syntactic account of NI, stranding of modifiers in an NI construction and the independent existence of null-headed NPs would require two different accounts. In a syntactic account, the stranded modifiers are created by the movement of the head out of the NP, thereby leaving the modifiers behind. Stranding is then directly tied to syntactically derived NI. However, in the lexical theory proposed here, null-head modifiers in NI constructions and those independent of NI constructions both have the same source.

2.2. TRANSitivity OF THE VERB. The incorporated noun does not satisfy an argument of the verb, but is semantically linked to a direct object argument. Thus, it is predicted that the complex verb in classifier NI constructions should always have the same number of arguments with and without NI. In the Northern Iroquoian languages, for example, the verb always agrees with its subject; when transitive, it also agrees with its object (Postal 1979 for Mohawk). When a noun is incorporated into the verb, the verb still has object agreement, even when there is no overt direct object.

The transitivity of a verb is often difficult to test in the Northern Iroquoian languages, because some of the transitive agreement prefixes overlap with the intransitive agreement prefixes. In particular, the prefixes on a transitive verb when the object is zoic, neuter, and sometimes masculine are also intransitive prefixes. This overlap is illustrated in the examples in 12. Ex. 12a is an example of an intransitive verb with the agreement marker ho-, indicating a third person masculine subject. In $12 \mathrm{~b}$ the verb is transitive, and ho- is used again, this time to indicate a third person masculine subject and a third person masculine object. Ex. $12 \mathrm{c}$ is another example of a transitive use of ho-, but this time the arguments are dropped (pro-drop). And finally, 12d provides an example of a transitive verb with an incorporated noun; again ho- is used (the agreement-3M.3Mis with 'pig' and not 'snout').

(12) Mohawk (Mithun \& Woodbury 1980:84-85, 92)

a. khná:?a ne kwískwis wa-t-ho-hí:le-ht-e?. then the pig AOR-DPL-3M-yell-CAUS-PUNC

'Then the pig yelled.'

b. khne éhlal yá:kA? wa-hó-hsel-e? ne ne kwískwis. then dog they.say AOR-3M.3M-chase-PUNC the the pig

'Then the dog chased the pig.'

c. kwah-óksak y-us-a-ho-tká:wa-ht-e? very-immediately TRS-ITER-AOR-3M.3M-release-CAUS-PUNC

'Immediately he released him.'

d. kwískwis y-a ?-t-ho-?nyukwal-ihshta-?.

pig TRS-AOR-DPL-3M.3M-snout-grab-PUNC 'He grabbed the pig's nose.'

In order to make a convincing argument concerning the transitivity of the verb in NI constructions, one must show that a transitive agreement prefix cooccurs with noun incorporation when the object is not third person zoic, neuter, 
or masculine, so that the prefix is distinct from the intransitive prefixes. Such a prefix is the Seneca agreement prefix shako-, which indicates agreement with a third person masculine subject and a third person feminine object. The examples in 13 show that when a noun is incorporated into the verb, the transitivity of the verb (as indicated by the $3 \mathrm{M} .3 \mathrm{~F}$ agreement prefix shako-) is unaffected.

(13) Seneca (Mithun \& Woodbury 1980:100)

a. Ta:h o:neh nä:h kyõ?öh da P-a-shako-kẽ-?

and now CONTRASTIVE QUOTATIVE NEG-AOR-3M.3F-see-PUNC katka?hoh, ne:? kyõ?ōh kê:s nekẽ? neh

anywhere ASSN QUOTATIVE repeatedly this the

$y e-k s-a$ ? $a-: h$.

F-child-small-sTAT

'And he didn't find the girl anywhere.'

b. O?-shako-ya Pt-ihsak-h-a?

AOR-3M.3F-body-look.for-DISLOC-PUNC

$h$-wa-ha-yaké-?-t.

TRS-AOR-3M-take.out-INCH-PUNC

'He went out to look for her.'

Crucially, the agreement prefix in $13 \mathrm{~b}$ is transitive.

Transitivity is also unaffected by NI in Rembarnga. Notice that, in the examples in 14, the incorporated noun is semantically related to the direct object; the direct object is phonologically null, but the agreement prefixes on the verb are transitive. (As pointed out to me by an anonymous reviewer, the ergative case is used for all agentive subjects-transitive or intransitive-and thus cannot be used as a criterion for transitivity.)

(14) Rembarnga (McKay 1975:79)

... piri-rut-manin?-min munaya-yi?

3sg.OBJ.3pl.TRANS.S.REL-road-build-PAST.PUNC white.man-ERG

'... where the white men build a road.'

The prediction of transitivity is borne out in Northern Iroquoian and in Rembarnga. There is no indication in the literature that incorporation ever affects the transitivity of the verb in these languages - a transitive verb remains transitive after NI has applied, and an intransitive verb remains intransitive after NI has applied.

2.3. Doubling AND NI. One last prediction regarding classifier NI is that a full NP should be able to co-occur with a classifier. In fact, the languages that have a system of classifiers on the verb also have what is called doubling, in which there is an incorporated noun in the verb, and the noun is repeated in the direct object NP position with more specific (or, depending on the language, at least as specific) information provided. This doubling phenomenon gives further evidence for the syntactic independence of NI and the direct object NP position; it is an example of NI without a null element.

Mithun 1984 describes doubling in some incorporating languages, showing that the complex verb is sometimes accompanied by a more specific NP in the 
object position, as exemplified in 15 and 16 for Iroquoian and 17 for Caddoan. Notice that in each case in 15-17 the independent NP is more specific than the incorporated noun, as required by the selectional restrictions placed on the verb by the incorporation process. For example, in 15 rabahbót 'bullhead' is a type of $t s y$ 'fish', and in $17 \mathrm{kassi}$ ' 'bead' is perceptually a type of Zic $^{2}$ 'a 'eye'.

(15) Mohawk (Mithun 1984:870)

Tohka niyohserá:ke tsi nahe? sha?té:ku nikú:ti rabahbót several so.it.year.numbers so it.goes eight of.them bullhead wahu-tsy-ahni:nu ki rake?niha. 3M.3N-fish-bought this my.father ${ }^{9}$

'Several years ago, my father bought eight bullheads.'

(16) Tuscarora (Williams 1976:60)

ne-hra-taskw-ahkw-ha? ha? tsi:r.

du-M-animal-pick.up-SERIAL EMPH dog

'He picks up domestic animals.' ( $\mathrm{He}$ is a dog catcher.)

(17) Caddo (Mithun 1984:865)

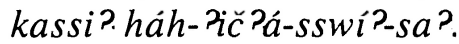

bead PROG-eye-string-PROG

'She is stringing beads.'

Finally, doubling is also attested in Rembarnga. The only difference between doubling in Iroquoian and Rembarnga is that Rembarnga does not require more specific information in the full NP.

(18) Rembarnga (McKay 1975:296)

kata ${ }^{2} \varnothing \quad$ par-kata ${ }^{2}-t a-\eta$ in.

paperbark-NOM 3sg.OBJ.3pl.TRANS.S-paperbark-stand-

(CAUS)-PAST.CONT

'They would spread paperbark (on the ground).'

The morphological form of the doubled $\mathrm{N}$ may be different, as long as the incorporated noun meets the selectional restriction that the NP be among the class of items specified by the incorporated noun. The morphological form of the incorporated noun - nuwa? in 19 is different from that of the independent noun kamunuyku?, though both are interpreted as meaning 'white ochre'. Notice that the selectional restriction is still placed on the verb-the direct object must be at least as specific as the incorporated noun. The restriction is simply looser in Rembarnga than it is in Iroquoian and Caddo.

(19) Rembarnga (McKay 1975:296)

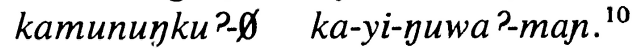

white.ochre-NOM 3sg.INTR.S-COMIT-white.ochre-went

'some white ochre arrived (i.e. bought by someone).'

The examples of doubling highlight the lexical nature of Classifier NI: there is no syntactic source for such doubled nouns. Further, there seem to be some

\footnotetext{
${ }^{9}$ In 15 Mithun 1984 glosses the agreement prefix wahu- as agreeing only with the subject (3M). See $n .7$ and $\$ 2.2$ for an explanation of the gloss given here.

${ }^{10}$ The verbal agreement in this sentence is intransitive because the verb is unaccusative, with one (internal) argument. Incorporation in ergative verbs is discussed more in $\$ 5$.
} 
language-particular differences in the requirement that the doubled NP be more specific than the incorporated noun. It is possible that the selectional restriction in Iroquoian and Caddo adds a requirement of specificity in addition to semantic compatibility, whereas Rembarnga only requires semantic compatibility. Again, if one were to adopt a syntactic account of NI, there is no syntactic source for the semantic restriction.

2.4. Southern Tiwa and West Greenlandic Eskimo. The analysis presented above for Classifier NI clearly predicts the grammatical properties associated with NI in Iroquoian, Caddo, and Rembarnga. However, NI in Southern Tiwa and West Greenlandic ${ }^{11}$ is not quite as clear-cut. In this section I will outline the properties associated with $\mathrm{NI}$ in these two languages to show where they are similar to and different from Iroquoian, Caddo, and Rembarnga, and finally I will mention a few possible solutions to the problems that they present.

First, Southern Tiwa NI patterns with the Classifier NI languages in that NI does not affect the transitivity of the verb. Thus, it is evident that the process of NI does not affect the argument structure of the verb. Both the input and the output of the word-formation rule is a transitive verb if the incorporated noun is semantically related to the direct object. If the incorporated noun is the sole argument of the verb (the subjects of unaccusative verbs obligatorily incorporate in Southern Tiwa when the subject argument is inanimate), the verb still agrees with that one (internal) argument. The agreement prefixes and the fact that transitivity is unaffected by NI are illustrated in examples 20-22 below. ${ }^{12}$ In 20 and 21 the verb agrees with the direct object (which happens to be null), and in 22 the verb agrees with the sole (subject) argument of the unaccusative verb. ${ }^{13}$

(20) Southern Tiwa (Allen et al. 1984:293)

Te-shut-pe-ban.

lsg.C-shirt-make-PAST

'I made the shirts.'

\footnotetext{
${ }^{11}$ West Greenlandic Eskimo is sometimes included in the literature as a language that has NI. Because it allows stranding, it appears that it should be included as a classifier incorporating language. However, as Alana Johns (personal communication, 1988) has pointed out to me, the evidence suggests that 'incorporation' in Eskimo is nothing at all like any of the incorporating languages discussed here. First, all verbs in Eskimo select for whether they take noun roots; thus incorporation applies only obligatorily, and to a restricted set of verbal affixes. Incorporating verbs in Eskimo might be better described as verbal affixes; the incorporating verbs are not stems that can stand alone without a noun. One might follow Sapir 1911 and Mithun 1986a in assuming that Eskimo does not have NI of the sort discussed here.

${ }^{12}$ Because of the complexity of the information encoded in the agreement prefixes of Southern Tiwa, I have used the glosses in Allen et al. 1984. The object agreement system in Southern Tiwa specifies number and animacy of the object. The agreement glosses referring to all third person subjects and objects can be summarized as follows (Allen et al. 1984):

A-singular, animate nouns plus several inanimate (e.g. karude 'car').

B-plural, animate plus several inanimate (as in A); singular, inanimate

C-plural, inanimate

${ }^{13}$ In ex. $22 \mathrm{NI}$ is actually obligatory, because the subject is inanimate and may not appear in subject position.
} 
(21) Southern Tiwa (Allen et al. 1984:294)

Seuanide i-mukhin-tuwi-ban.

man A.B-hat-buy-PAsT

'The/a man bought the/a hat.'

(22) Southern Tiwa (Allen et al. 1984:300)

$I-k$ 'uru- $k$ ?euwe-m.

B-dipper-old-PRESENT

'The dipper is old.'

The gloss ' $1 \mathrm{sg}$ ' of the agreement marker in 20 refers to subject agreement, and the letters A, B, and C in the glosses are explained in $\mathrm{n}$. 13. These examples show that NI in Southern Tiwa does not affect the argument structure of the simple verb (as indicated by the agreement marker on the verb), suggesting that Southern Tiwa is a Classifier NI language. ${ }^{14}$

In West Greenlandic, the transitivity picture is slightly less clear. When a noun appears incorporated into a verb in West Greenlandic, the verb is always intransitive, and any stranded material appears in instrumental case. Incorporation in West Greenlandic is illustrated in 23; the verb in 23 has intransitive agreement (agrees only with the subject).

(23) West Greenlandic (Sadock 1980:307)

Kusanartumik sapangarsivoq.

beautiful.NM.INST bead.get.INDIC.3sg

'He bought a beautiful bead.'

However, as Sadock 1980 explains, object agreement on the verb is sensitive to the definiteness of the direct object. Only definite direct objects get agreement on the verb, and all indefinite objects appear in instrumental (rather than absolutive) case. It is possible that the transitivity of the verb with a noun incorporated into it is affected by lack of definiteness, rather than by incorporation itself.

Southern Tiwa and West Greenlandic pattern with Classifier NI languages in that they have stranding. Numerals (ex. 24) and demonstratives (ex. 25) can be left stranded in an NI construction in Southern Tiwa, and ex. 23 above illustrates stranding of an adjective in West Greenlandic.

(24) Southern Tiwa (Allen et al. 1984:295)

$$
\begin{aligned}
& \text { Wisi bi-seuan-mũ-ban. }{ }^{15} \\
& \text { two 1sg. B-man-see-PAST } \\
& \text { 'I saw two men.' }
\end{aligned}
$$

\footnotetext{
${ }^{14}$ Agreement in 20 appears not to be with the incorporated $\mathrm{N}$, which is neither singular nor plural, but with the null head of the direct object NP, which must be plural. The incorporated noun and the null noun are syntactically and lexically independent.

${ }^{15}$ The agreement in 24 points to another indication of the existence of null-head modifiers. The agreement marker is the only piece of information that carries the plural meaning of the noun seuan 'man' in 24 . The verb's plural marker does not actually agree with the incorporated noun stem, which cannot have a plural marker (only noun stems incorporate). The verb agrees in number with the direct object NP, which in this case is phonologically null. The fact that the agreement marker is the only indication of plurality of the object is a natural consequence of the lexical process of NI.
} 
(25) Southern Tiwa (Allen et al. 1984:295)

Yede a-seuan-mü-ban.

that 2sg.A-man-see-PAST

'You saw that man.'

Southern Tiwa and West Greenlandic diverge from the canonical Classifier NI languages on the property of doubling: they do not allow any doubling at all. This poses an apparent counterargument to the analysis of Classifier NI presented here. Any language in which the verb retains its transitivity and allows stranding with NI is predicted to have doubling as well. However, I will outline here two possible explanations for the lack of doubling.

One possible solution to the doubling problem would be to show that the NPs derived from doubling are not well-formed NPs in the syntactic positions in question. In Southern Tiwa, for example, there is a hierarchy of person and animacy that often drives NI. The hierarchy itself is complex, but basically if the direct object is of a certain sort (inanimate, for example), then the head noun root of the object must incorporate (Allen et al. 1984, Sadock 1985b). ${ }^{16}$ It appears that nouns that obligatorily incorporate simply may not appear in object position (a similar hierarchy exists for determining what may or may not passivize). In order to test for doubling, it is necessary to choose a noun that optionally incorporates; only such nouns may appear either incorporated into the verb or in direct object position. This narrows the possible nouns to two categories: human singular nouns when the subject is first or second person and animate nonhuman singular nouns that are modified by a demonstrative or numeral (see n. 16 for a brief description of the hierarchy). The prediction is that there should be a limited number of constructions in which doubling is permitted. In fact, Baker 1988b cited data concerning this prediction with a singular human object, with a non-third-person subject, and it is ungrammatical (Baker attributed 26d to personal communication from Donald Frantz):

(26) Southern Tiwa (Allen et al. 1984:294-95)

a. Ti-seuan-mü-ban.

1s.A-man-see-PAST

'I saw the/a man.'

b. Wim?a a-seuan-mü-ban.

one 2s.A-man-see-PAST

'You saw one man.'

c. Wim?a seuan-ide a-mü-ban.

one man-suF 2s.A-see-PAST

'You saw one man.'

d. ${ }^{*}$ Wim?a seuan-ide a-seuan-mü-ban. one man-suF 2s.A-man-see-PAST

'You saw one man.'

\footnotetext{
16 The incorporation hierarchy is as follows: all inanimate objects and inanimate subjects of ergative verbs must incorporate; all nonhuman animate objects must incorporate, unless they are singular and are modified by a numeral or demonstrative (these optionally incorporate); human singular objects must incorporate when the subject is third person; all other human objects optionally incorporate.
} 
Ex. 26 thus provides counterevidence to the argument that doubling is out simply because the NPs are independently ill-formed. Ex. $26 \mathrm{~b}$ establishes that the NI construction is in general good, and $26 \mathrm{c}$ establishes that the NP is independently well-formed and can occur in object position. However, the cooccurrence of an incorporated noun and a doubled object is out (26d).

A second possible explanation for the lack of doubling within the lexical approach concerns the selectional restriction placed on the verb by the incorporated noun. In some incorporating languages (e.g. Rembarnga) the direct object NP can mimic the incorporated noun completely, giving identical information. In other languages, however (e.g. Iroquoian), the direct object NP must provide more (specific) information than the incorporated noun; otherwise it must be empty (pro). It is possible that the selectional restrictions placed on the verb in Southern Tiwa and West Greenlandic exemplify the other extreme: The head of the direct object must not duplicate any of the information in the incorporated noun. The restriction may be so strict as to rule out any instance of doubling. Thus, the selectional restrictions would forbid doubling, rather than the rule of NI.

Ken Hale and Joan Bresnan (personal communication, 1988) independently suggested to me that I explore the possibility of a solution along these lines. It may be that in some languages, the incorporated noun carries more noun (possibly referential) features than in others. In languages like the Iroquoian languages, Caddo, or Rembarnga, the incorporated noun has few noun-like features, and is truly a classifier. It is for this reason that an incorporated noun is compatible with a fully specified NP; the incorporated noun simply adds a selectional restriction on the verb. However, in a language like Southern Tiwa or West Greenlandic, the incorporated noun carries with it a full specification of noun head features. It is the existence of these noun features that prohibits doubling-doubling can only occur when the features of the head are not already fully specified elsewhere (in this case on the verb). This is parallel to Hale's 1987 obligatory pro-drop in Irish and Dogrib, and to Bresnan \& Mchombo's 1987 account of object agreement in Chichewa. Hale and Bresnan \& Mchombo show that when an agreement marker appears on the verb, the argument (subject for Irish, object for Dogrib and Chichewa) must be absent (only phonologically for Hale). Hale explains this by suggesting that the agreement marker is super rich, in fact so rich as to force pro-drop (pro-drop is generally thought to be licensed by a property of rich agreement). Bresnan \& Mchombo suggest that the referential features on the agreement marker cannot be duplicated by referential features on the object NP. Thus, if there are fully specified noun features on the agreement marker, these cannot be duplicated by fully specified features in the independent NP.

The complementary distribution of the agreement markers and the NP is identical to the lack of doubling in Southern Tiwa and West Greenlandic NI, except that the former is at the NP level, whereas the latter is at the $\mathrm{N}^{0}$ level. It is possible that the incorporated noun in Southern Tiwa and West Greenlandic has enough referential, or noun-like, features that it cannot co-occur with an object head. 
If the lexical account of Southern Tiwa and West Greenlandic NI is correct, then another prediction of this approach is that null-head modifiers (stranded modifiers) should occur independent of NI, as in Northern Iroquoian and Caddo. This prediction is clearly borne out in West Greenlandic. In ex. 27a the noun root for 'dog' is incorporated and the modifier angisuumik 'big' appears with a null head in object position. In $27 \mathrm{~b}$, the null-headed modifier angisuumik is again in object position with a null NP head, but there is no noun root in the verb.

(27) West Greenlandic (Sadock 1980:309)

a. Angisuumik qimmeqarpoq.

big.NM.INST dog.have.INDIC.3sg

'He has a big dog.'

b. Angisuumik unataavoq.

big.NM.INST beat.APASS.INDIC.3sg

'He beat a big one.'

This provides strong evidence that the Classifier analysis of NI in West Greenlandic is essentially correct, and that the failure of doubling is due to some other factor.

In Southern Tiwa the only stranded modifiers associated with NI are numerals and demonstratives. If the lexical approach to Southern Tiwa is right, the only null-head modifiers in the language should be numerals and demonstratives. This appears to be the case for Southern Tiwa (Donald Frantz, personal communication 1989). Numerals and demonstratives can stand alone with no head noun even when there is no noun incorporated into the verb. Such stranding is illustrated in 28 .

(28) Southern Tiwa (Donald Frantz, personal communication 1989)

a. Yede a-mü-ban. that 2s.A-see-PAST

'You saw that.'

b. Wisi bi-mü-ban.

two 1s.B-see-PAST

'I saw two.'

From 28 it is clear that stranded numerals and demonstratives are independent of NI for this language, as is clearly predicted by my theory. Donald Frantz further reports that numerals and demonstratives appear to be the only nullhead modifiers possible in the language. Again, there is strong evidence, from the independence of NI and null-head modifiers, that the lexical account of NI is correct, but that the failure to double is due to some independent factor.

An altogether different approach to the problem would be to show that NI in Southern Tiwa and in West Greenlandic represents yet a third type of incorporation, either one as yet unexplored or one that is syntactically derived by, for example, $\mathrm{X}^{0}$ movement as in Baker 1988a,b or coanalysis as in Sadock 1985a. The properties that this third type of NI would have to explain are (i) the fact that NI itself does not affect transitivity of the verb; (ii) the stranding facts; (iii) the lack of doubling; and (iv) the specific selectional restrictions that 
the incorporated noun places on the verb. Again, incorporation would often be forced in Southern Tiwa by the independently existing animacy/person hierarchy, which prevents certain NPs from appearing in direct object position. Depending on the animacy/person of the DO and the subject, the object either optionally or obligatorily incorporates.

It is apparent from this discussion that Southern Tiwa and West Greenlandic NI do not, on the face of it, fit perfectly into the theory proposed in this paper. I have suggested two possible reasons for this: the two languages do have the lexical Classifier NI just like Iroquoian, Caddo, and Rembarnga, but do not allow doubling for reasons quite independent of NI; or these languages display a process of NI that this theory does not address (a syntactic process, for example). However, the fact that Southern Tiwa and West Greenlandic do not allow doubling in no way diminishes the account of NI in the other languages. In fact, if a syntactic account allows doubling in some languages, then it should allow it in these two languages as well. Conversely, if a syntactic account predicts that there will be no doubling (as in Southern Tiwa and West Greenlandic), then it also must predict no doubling in other languages, which is simply not the case (see $\S 4$ for a full exposition of this point). Therefore, the lack of doubling in these languages does not lend support for either the syntactic or the lexical approach to NI-it is a problem equally for both accounts. ${ }^{17}$

3. COMPOUND NOUN INCORPORATION. In Compound NI, the direct object argument of the simple verb is satisfied, so that no direct object can co-occur with NI. The outcome of Compound NI is shown schematically in 29.

(29) unroll (x, y) $\rightarrow$ mat-unroll (x)

hunt $\quad(x, y) \rightarrow$ fish-hunt $\quad(x)$

Three predictions concerning the grammatical consequences of Compound NI follow from this one fact about the argument structure change: (i) the complex verb will have one fewer argument than the simple (unincorporated) form, making the verb intransitive whenever NI affects the direct object argument; (ii) there will be no stranding; and (iii) there will be no doubling. If a direct object NP were to co-occur with Compound NI, a Theta-Criterion violation would result, because the complex verb does not have a theta-role to assign to an object. This is similar to synthetic compounds in English (Selkirk 1983, Lieber 1983). Though in English all such compounds are deverbal $\left({ }^{*}\right.$ meat-eat vs. meat-eater), the noun element may satisfy an argument of the verb element, and that argument cannot occur outside the compound (*Bill was a meat-eater of rare beef). In the following sub-sections I show that in Compound NI languages, when a noun and verb combine, the result is an intransitive verb, and no stranding or doubling takes place. The languages that appear to allow Compound NI are some Polynesian languages (Chung 1978:183-89, Rehg 1981:20914, Seiter 1980:69-78) and some Micronesian languages (Harrison 1976:161-

\footnotetext{
${ }^{17}$ Donald Frantz (personal communication, 1989) pointed out to me that there are some aspects of NI in Southern Tiwa that must be addressed before Southern Tiwa NI is fully understood. These include NI in passive and causative constructions. These are clearly important for a complete understanding of NI in Southern Tiwa, but they are beyond the scope of this paper.
} 
63, Lee 1975:263-77), and possibly some of the Mayan languages (Robertson 1980:136-38), though I will specifically address only Polynesian and Micronesian languages here.

3.1. Transitivity of The verb. If a language has Compound NI, the complex verb is expected to be intransitive when a direct object is incorporated, and thus should behave like any intransitive verb in the language. The evidence on case marking in the Polynesian languages is overwhelmingly in favor of the prediction of intransitivity.

Some Polynesian languages have ergative case marking: the subject of a transitive verb is marked ergative, and the object is marked absolutive. When the verb is intransitive, however, the subject is absolutive. In Samoan and Niuean, when a noun incorporates into the verb, the subject bears absolutive case, indicating that the verb is intransitive. Examples from Samoan and Niuean appear in 2 above and in 30 and 31.

(30) Samoan (Mithun 1984:850)

a. Po io a:fea $e$ tausiai e ia tama?

$\mathrm{Q}$ PRED when TNS care PRN ERG he child

'When does he take care of children?'

b. Po ?o a:fea e tausi-tama ai ?oia?

$\mathrm{Q}$ PRED when TNS care-child PRN ABS-he

'When does he baby-sit?'

(31) Niuean (Seiter 1980:267)

a. kua ta: he tama e taufakatino aki $e$ malala. PERF draw ERG child ABS PL picture with ABS charcoal

'The child has been drawing pictures with a charcoal.'

b. kua ta: fakatino $e$ tama aki $e$ malala.

PERF draw picture ABS child with ABS charcoal

'The child has been drawing pictures with a charcoal.'

NI reveals itself in $30 \mathrm{~b}$ and $31 \mathrm{~b}$ in several ways. The incorporated noun has no inflection (no plural marker in $30 \mathrm{~b}$ ). The incorporated noun is adjacent to the verb (though not orthographically part of the verb). Niuean has VSO word order and thus the object would not ordinarily appear adjacent to the verb. Finally, the subject appears in absolutive case, and the incorporated noun has no case marker. In some other Polynesian languages, the verb has a transitive/ intransitive marker. When the object of a transitive verb is incorporated, the verb appears in the intransitive form. Ponapean examples appear in 32 and 33.

(32) Ponapean (Rehg 1981:209-10)
a. I pahn ihkos-e likou ehu.
I will pleat-TRANs dress a
'I will pleat a dress.'
b. I pahn ihkos-ø.
I will pleat-INTR
'I will pleat.'
c. I pahn ihkos-Øl-likou.
I will pleat-INTR-dress
'I will dress-pleat.'


(33) Ponapean (Rehg 1981:212)

a. I pahn perek-i lohs.

I will unroll-TRANS mats

'I will unroll mats.'

b. I pahn perek-Øb-los.

I will unroll-1NTR-mat

'I will mat-unroll.'

If transitive marking shows up in conjunction with NI, the sentence is ungrammatical, as 34 shows. In 34 a there is no incorporation, and the verb is transitive (as indicated by ergative case on the subject). In $34 \mathrm{~b}$, the object is incorporated, and the verb is intransitive. Ex. $34 \mathrm{c}$ is ungrammatical; the noun is incorporated, and the subject is marked ergative, indicating that the verb is transitive.

(34) Tongan (Chung 1978:152)

a. NaPe haka ?e he sianá Pa e ika.

PAST cook ERG the man ABS the fish

'The man cooked a fish.'

b. Na?e haka-ika ?a e sianá.

PAST cook-fish ABS the man

'The man cooked fish.'

c. ${ }^{*} N a$ Pe haka-ika ${ }^{2} e$ he sianá.

PAST cook-fish ERG the man

('The man cooked fish.')

The data presented in 30-34 indicate that, in the Polynesian languages, the verb is always intransitive when the object is incorporated. In fact, Rehg (1981:209-14), Lee (1975:263), and Robertson (1980:138) describe the process of so-called 'object incorporation' as making an otherwise transitive verb intransitive.

3.2. Stranding of MOdifiers. In languages with compound NI, there should be no stranding of determiners or of modifiers. For a modifier or determiner to be stranded in conjunction with NI, the object argument would have to be expressed outside the verb. Without an object, there can be no such stranded elements. In fact, Polynesian does not allow stranding or any modification of the incorporated noun at all. Examples of attempts to modify an incorporated noun appear in 35-36. Ex. 35a has a modified direct object. In 35b the object is incorporated. Exx. 35c-d show that the incorporated object cannot be modified. Thus, stranding in the Compounding languages is impossible.

(35) Kusaiean (Lee 1975:271)

a. El twem-lah mitmit sahfiht sac.

He sharpen-PAST knife dull the

'He has sharpened the dull knife.'

b. El twetwe mitmit-lac.

He sharpen knife-PAST

'He has knife-sharpened.' 
c. *Nga twetwe mitmit sac.

I sharpen knife the

('I knife-sharpen the Ø.')

d. *Nga twetwe mitmit sahfiht sac.

I sharpen knife dull the

('I knife-sharpen the dull Ø.')

(36) Ponapean (Rehg 1981:212)
a. I pahn perek-i lohs-o.
I will unroll-TRANS mat-that
'I will unroll that mat.'
b. *I pahn perek-Ø-los-o.
I will unroll-INTR-mat-that
('I will unroll that mat.')

The Polynesian and Micronesian languages do not show any evidence of having null-head modifiers, as found in Iroquoian and Caddo. However, if a Compound NI language did have null-head modifiers, there is a clear prediction concerning the interaction of NI and null-head modifiers: they would not interact at all. Because the argument is satisfied by the NI word-formation process, there is no NP related to the incorporated noun, and thus there can be no NP with a null head related to the incorporated noun.

3.3. Doubling. Doubling, like stranding, requires an argument outside the verb; because the complex verb in Compound NI has no object theta-role to assign, there can be no doubling. Doubling, too, is unattested in the literature on NI in the Polynesian and Micronesian languages.

3.4. Summary: COMPOUND NOUN INCORPORATION. In this section I have argued for the existence of a type of incorporation distinct from the classifier type. In essence I claim that what in the literature is called object or noun incorporation for Polynesian is simply compounding, much like the compounding one finds in English (with the one major difference that English only allows deverbal compounds). Thus, in Polynesian, the compound satisfies an argument of the simple verb. In languages with this sort of incorporation one does not find stranding or doubling, and when the direct object argument is incorporated the verb becomes intransitive, as is predicted by the analysis proposed here.

4. Syntactic acCOUnts of NOUn InCORPORATION. There are two detailed syntactic analyses of NI in the literature-Baker's 1988a movement account and Sadock's 1985a autolexical approach. The grammatical properties predicted to be associated with NI in these accounts are quite different from those predicted by the analysis outlined in $\$ 2$ and $\$ 3$ of this paper.

In the movement analysis, direct object nouns are incorporated into verbs via $\mathrm{X}^{0}$ movement (Baker 1988a); that is, the head of the direct object NP moves out of object position into the verb, leaving a trace behind. The result of this move is diagrammed in 37 (Baker 1988a:83). 
(37)

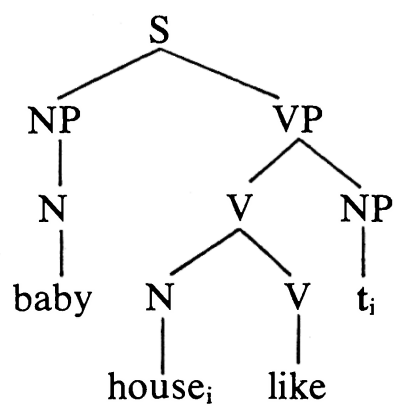

In this analysis, when a noun moves, any modifiers or determiners in the direct object NP are left behind; thus, the stranding facts are obtained.

Another syntactic analysis of NI has been proposed by Sadock 1985a. In Sadock's Autolexical Syntax, morphology and syntax have completely independent representations that meet at the word level. This is relevant for NI, in which the morphology has one representation, with the verb and the incorporated noun combined in one word, and the syntax has a different representation, with the noun in object position. The linear order of the morphemes in the sentence is determined by the morphological rather than the syntactic representation; therefore, if a noun root appears morphologically inside the verb, the surface sentence will be an NI construction. Sadock's approach (like that of this article) further assumes that the Compound NI languages derive NI constructions by compounding. In the autolexical system the existence of a compound structure would only appear in the morphological structure, and thus compounding would be invisible to the syntax.

A fundamental problem with both of these syntactic accounts is that they do not predict the cluster of grammatical properties shown in this paper to be associated with NI. A summary of these properties is listed in Table 2, which includes the two types of incorporation discussed in this paper. Given the results of the brief analysis of Southern Tiwa and West Greenlandic in \$2.4, it is entirely possible that there is a third type of NI, whose properties are not yet completely understood. However, I will discuss only the predictions of the syntactic analyses with respect to the two types of incorporation represented in Table 2.

\begin{tabular}{ll}
\multicolumn{1}{c}{ CLASSIFIER NI } & \multicolumn{1}{c}{ Compound NI } \\
- argument structure unaffected by NI & - argument satisfaction within complex verb \\
- stranding of modifiers & - no stranding of modifiers \\
- doubling outside verb & - no doubling outside verb
\end{tabular}

TABLE 2. Cluster of properties associated with noun incorporation.

First, the movement account predicts that any verb with an incorporated direct object should be transitive. This follows from the claim that a trace is left behind in object position; the transitivity of the verb should be unaffected by incorporation. This simply is not the case for an entire class of languages (e.g. the Compound NI languages). A syntactic movement approach requires a separate account of the transitivity facts in those instances of NI that result in an intransitive verb. Baker 1988a provides such an account by proposing 
that the NP out of which a noun is incorporated may get syntactic case, but need not; however, there is no a priori way to predict whether a given language is one that allows caseless NPs associated with NI.

The autolexical approach encounters problems only with the Classifier NI languages, because this approach would treat Compound NI in much the same way that my theory would. However, for the class of languages which, I have argued, have Classifier NI, the autolexical approach would assign two distinct (and mismatched) representations for every sentence: a morphological representation and a syntactic representation. In order to get the result that, in Classifier NI languages, NI does not affect the transitivity of the verb, it must be stipulated that the transitivity of a sentence is determined by the syntactic representation and not by the morphological representation, yielding no transitivity difference between an NI construction and a nonincorporated construction. There is no a priori, or principled, reason to believe that a given grammatical property, such as transitivity, should be determined by the syntactic representation rather than the morphological representation. (For a full exposition on this point, see Baker 1988c.) In the lexical analysis proposed here, however, the transitivity facts fall out naturally.

Second, the movement account predicts that stranding should occur in all incorporating languages. If the head of a direct object NP incorporates by movement, then it should be possible for modifiers to be left stranded. Again, this is not true for Compound NI languages. The autolexical account does accurately predict that, in the languages that it accounts for (the Classifier languages in Table 1), stranding always applies. However, neither syntactic account has anything to say about the independently well-formed null-head modifiers, which exist in all of the Classifier NI languages. Both syntactic approaches would have to attribute stranding in NI and null-head modifiers in nonincorporated constructions to completely different grammatical properties.

A third prediction of the syntactic approaches is that doubling should not occur at all. If the NP head is moved out of the object position (movement account), or is morphologically joined with the verb but morphologically absent from the NP (autolexical account), then it should not appear both incorporated and in direct object position. Doubling does occur in languages that have Classifier NI, however. Again, Baker 1988a explains the doubling facts by claiming that the doubled NP is actually an adjunct and not the argument from which the noun root incorporates. This would be a feasible solution, except that one would expect to find the co-occurrence of an incorporated noun, the argument NP with stranded modifiers, and a doubled adjunct. ${ }^{18}$ Finally, the selectional restrictions placed on a doubled NP do not follow from the adjunct account of doubling, as they do from the lexical account proposed here.

In sum, then, the syntactic approaches to NI lead one to expect certain grammatical properties of transitivity, stranding, and doubling to be associated

\footnotetext{
${ }^{18}$ Of course, it is always possible to add as many appositional phrases as one wants, all modifying one argument (for example, in English 'The man bought a dog, a very large dog, a truly ferocious animal ...'). This ability to add appositional phrases makes it difficult to distinguish between doubled argument and adjunct in incorporating languages.
} 
with NI constructions. In fact, however, the predicted properties are not manifested in the data across languages, and in particular the existence of null-head modifiers in non-NI constructions and the existence of doubling are unexpected and unexplained in syntactic analyses of NI.

5. CONCLUSION AND ADDITIONAL REMARKS. One remaining problem concerning NI is the question of what can and cannot incorporate.$^{19}$ Both the Classifier and the Compound types display a subject/object asymmetry-NI is generally described as applying to direct objects. The only subjects that incorporate are subjects of unaccusative verbs, as illustrated in 38 .

(38) Onondaga (Woodbury 1975:10)
a. kahihwi ne? ohsahé ?ta?
3N.spill.cause.ASP ART 3N.bean(s).SUF
'The beans are spilled.'
b. kahsahe Ptahíhwi. 3N.bean(s).spill.cause.ASP
'Beans are spilled.'

Subjects of unaccusative verbs are generally analyzed as underlying direct objects (Burzio 1986:27-31, Perlmutter 1978), so the subject/object distinction holds. This subject/object asymmetry in part led to the syntactic movement analysis; the direct object position is properly governed by the verb, and thus the moved noun stem governs its trace, satisfying the Empty Category Principle (ECP). It is a challenge to a lexical theory to match the syntactic explanation of the subject/object asymmetry in NI.

There is some evidence that NI does not apply exclusively to direct objects. Instrumentals incorporate in Nahuatl (Baker 1988a, Mithun 1984, Sapir 1911), means phrases incorporate in Niuean (Seiter 1980), and some locatives incorporate in Samoan (Chung 1978), though none of these phrases is ever a direct object. Although a clear subject/nonsubject asymmetry exists, it is not clear that the distinction is between subject and direct object, rather than between subject and nonsubject. Mithun 1984 has attempted to explain these facts by assuming that themes and patients incorporate. Again, this runs into problems with the incorporation of instrumentals, means phrases, and locatives in some languages; these are not themes or patients, yet they incorporate.

\footnotetext{
19 Another issue which I have not addressed, and which I only mention briefly here, is the relation of possessor arguments to NI. In Northern Iroquoian, when a possessor is stranded by a null object argument in an NI construction, the verb agrees with the possessor, as if the possessor were the direct object. This is commonly called 'possessor raising' (Baker 1988a, Mithun 1984):

(i) Mohawk (Mithun \& Woodbury 1984:93)

$$
\text { ... s-a-ho-hna } t s-l i \text { Pk-hú:-n-e? ne kwiskwis... }
$$$$
\text { COIN-AOR-3M.3M-ass-bite-REP-AMB-PUNC the pig }
$$$$
\text { 'while he kept biting the pig's ass/the ass of the pig' }
$$

In this example, the object agreement is with the possessor kwiskwis 'pig' (third person masculine) rather than with 'ass'. (Rembarnga also has possessor raising.) Mithun (1984, personal communication 1986) has suggested that in all cases of possessor raising the possessor has a benefactive reading associated with it. It may be that what is translated as a possessor modifier is actually a possessor/benefactive argument (though this is apparently not true for Southern Tiwa). If this is true, then so-called possessor raising would not actually exist.
} 
Another possibility is that NI distinguishes between internal and external arguments: external arguments never undergo incorporation, whereas virtually any internal argument may do so (though any given language will choose among the possible internal arguments). ${ }^{20}$ Still to be explained, however, is the apparent fact that goals and benefactives never incorporate in any language. The internal/external (or theta-role) generalization of the subject/object asymmetry is not limited to NI. Notice that in English compounding, external arguments cannot undergo compounding; only internal arguments can (Lieber 1983), and goals and benefactives are once again excluded. Because an internal/external distinction is already built into theories of argument structure, such a solution does not require the addition of extra machinery.

Another interesting prediction of the lexical theory concerns the relation between the properties of null-head modifiers and the two types of NI. In my lexical theory, the two word-formation rules (Compound NI and Classifier NI) are independent of the existence of null pro-forms. This independence predicts four different manifestations of the two processes, as listed in $39 .{ }^{21}$

(39) Predicted language types

\begin{tabular}{ll}
\multicolumn{1}{l}{ Compound/Classifier } & Null PRO-FORMS \\
a. Compound NI & Yes \\
b. Compound NI & No \\
c. Classifier NI & Yes \\
d. Classifier NI & No
\end{tabular}

Thus far we have evidence for the existence of $39 \mathrm{~b}$ and 39c. If NI and the occurrence of null-headed NPs are truly independent, languages manifesting the combination of properties in 39a and 39d should exist as well. In fact, Ken Hale (personal communication, 1988) suggests that the Tanoan language Jemez might be a type 39d language-one with Classifier NI but no stranding (i.e. no null NP heads). Ideally, of course, one would want to fill out the paradigm in 39.

To sum up, this paper has shown (i) that there are at least two distinct types of NI, one that results in selectional restrictions placed on the verb and one that results in argument satisfaction; (ii) that noun incorporation results from a lexical combination of words (word-formation rules); and (iii) that stranding facts follow from independent principles of syntax-the existence of null arguments (pro-drop) and of null NP heads. The two types of NI within a lexical account correctly predict a cluster of grammatical properties associated with NI across several languages and language groups. Further, I have shown that only a lexical account of NI can tie together the stranding facts within NI and the independently existing null-head modifiers as originating from the same grammatical source.

\section{REFERENCES}

Allen, Barbara J.; Donna B. Gardiner; and Donald G. Frantz. 1984. Noun incorporation in Southern Tiwa. IJAL 50.292-311.

\footnotetext{
${ }^{20}$ Jane Grimshaw pointed this possible explanation out to me.
}

${ }^{21}$ Thanks to Alan Prince for pointing this out to me. 
BAKER, MARK C. 1988a. Incorporation: A theory of grammatical function changing. Chicago: Chicago University Press.

--. 1988b. On morphological and syntactic objects: A reply to DiSciullo and Williams. McGill University, Ms.

- 1988c. Against reanalysis of heads. McGill Working Papers, May 1988:35-60.

Bresnan, JoAn, and SAm A. Mсhombo. 1987. Topic, pronoun, and agreement in Chicheŵa. Lg. 63:741-82.

Burzio, Luigi. 1986. Italian Syntax. Dordrecht: Reidel.

Chung, Sandra. 1978. Case marking and grammatical relations in Polynesian. Austin: University of Texas Press.

DiSciullo, Anna Maria, and Edwin Williams. 1987. On the definition of word. (Linguistic Inquiry Monograph 14.) Cambridge, MA: MIT Press.

Hale, Ken. 1987. Agreement and incorporation in Athabaskan and in general. MIT, MS.

HarRison, Sheldon P. 1976. Mokilese reference grammar. Honolulu: University Press of Hawaii.

LeE, KeE-Dong. 1975. Kusaiean reference grammar. Honolulu: University Press of Hawaii.

Lieber, Rochelle. 1983. Argument linking and compounds in English. LI 14.251-85.

McKay, Graham Richard. 1975. Rembarnga: A language of Central Arnhem Land. Australian National University dissertation.

Mithun, MarianNe. 1984. The evolution of noun incorporation. Lg. 60.847-94.

- 1986a. On the nature of noun incorporation. Lg. 62.32-37.

- $1986 \mathrm{~b}$. When zero isn't there. Berkeley Linguistics Society $12.195-411$.

- and HANNI WoodBury (eds.) 1980. Northern Iroquoian texts. (IJAL Native American Texts Series, 4.) Chicago: University of Chicago Press.

Perlmutter, David M. 1978. Impersonal passives and the unaccusative hypothesis. Berkeley Linguistics Society 4.157-89.

Postal, Paul M. 1979. Some syntactic rules of Mohawk. New York: Garland.

Rehg, Kenneth L. 1981. Ponapean reference grammar. Honolulu: University Press of Hawaii.

ROBERTSON J. S. 1980. The structure of pronoun incorporation in the Mayan verbal complex. New York: Garland.

SADOCK, JERROLD M. 1980. Noun incorporation in Greenlandic: A case of syntactic word formation. Lg. 56.300-19.

- 1985a. Autolexical syntax: A proposal for the treatment of noun incorporation and similar phenomena. Natural Language and Linguistic Theory 3.379-439.

- $1985 \mathrm{~b}$. The Southern Tiwa incorporability hierarchy. IJAL 51.568-72. 1986. Some notes on noun incorporation. Lg. 62.19-31.

SAPIR, EDWARD. 1911. The problem of noun incorporation in American languages. American Anthropologist 13.250-82.

Seiter, William J. 1980. Studies in Niuean syntax. New York: Garland.

Selkirk, Elizabeth O. 1983. The syntax of words. (Linguistic Inquiry Monograph 7.) Cambridge, MA: MIT Press.

Williams, Marianne Mithun. 1976. A grammar of Tuscarora. New York: Garland.

WoODBURY, HANNI. 1975. Onondaga noun incorporation: Some notes on the interdependence of syntax and semantics. IJAL 41.10-20.

Program in Linguistics \& Cognitive Science

Brandeis University

Waltham, MA 02254
[Received 14 March 1988; revision received 16 December 1988; accepted 22 December 1988.] 